\section{Application Of Signal Frequency Ortogonal Multiplexing In Dvb-T Standard}

\section{N.I. Juraeva}

Phd, Karshi Branch Of Tashkent University Of Information Technologies Named After Muhammad Al-Khwarizmi Uzbekistan

\section{J.H. Hamraev}

Assistant, Karshi Branch Of Tashkent University Of Information Technologies Named After Muhammad Al-Khwarizmi Uzbekistan

\section{G open ACCESS}

The American Journal of Engineering And Technology

JULY 2020

Page No.: 35-39

Volume-II Issue-VII

PUBLISHED: 30 JULY 2020

www.usajournalshub.com/inde

x.php/tajet

Copyright: Original content from this work may be used under the terms of the Creative Commons Attribution 4.0 licence.

\title{
Abstract
}

The orthogonal frequency multiplexing, defined by the abbreviation OFDM, provides a significant increase in the bandwidth of the radio channel due to the improvement in spectral efficiency. In addition, the use of OFDM allows the transmission speed to be increased without increasing the frequency range or modulation level. Therefore, OFDM is used in modern wireless systems, such as IEEE 802.11 (Wi-Fi) and IEEE 802.16 (WiMAX), as well as in wired ADSL.

Keywords: ortogonal multiplexing, DVB-T standard, OFDM, IEEE, ADSL, BWA.

\section{Introduction}


In broadband wireless (BWA) systems, the main disruptive factor of a digital channel is the interference of multipath reception.

Such noise is very specific for receiving broadcasts in cities with dense buildings because it reflects radio signals from buildings and other structures many times.

Briefly outline the main pros and cons of OFDM:

\section{Advantages:}

- High efficiency of radio frequency spectrum utilization due to the fact that the rectangular shape of the spectrum are almost subcarriers.

- Simple hardware: basic operations are performed using digital processing methods.

- Good resistance to intersymbol interference (ISI) and intercarrier interference (ICI intercarrier interference).

\section{The Main Findings And Results}

The result is a commitment to reproduction. Ability to use different modulation schemes for each subcariator, allowing flexibly varying noise immunity and increasing data transfer rates.

\section{Disadvantages:}

- High frequency and time synchronization required.

- Sensitivity to the mobile Doppler effect limits the use of OFDM in mobile systems.

- "What is not ideal in modern receivers and transmitters causes phase noise, which limits the performance of the system.

- The protection range used in OFDM to combat multi-directional propagation reduces the spectral efficiency of the signal.

Despite all the shortcomings, OFDM is the perfect solution for modern network architecture operating in the metropolis. Technical progress and market dynamics are 
forcing manufacturers to constantly improve existing technologies. As a result, devices that use different OFDM modifications have emerged.

OFDM is a completely new type of modulation in which a serial digital stream is converted into a large number of parallel streams (sub-streams) and each of them is transmitted to a separate carrier.

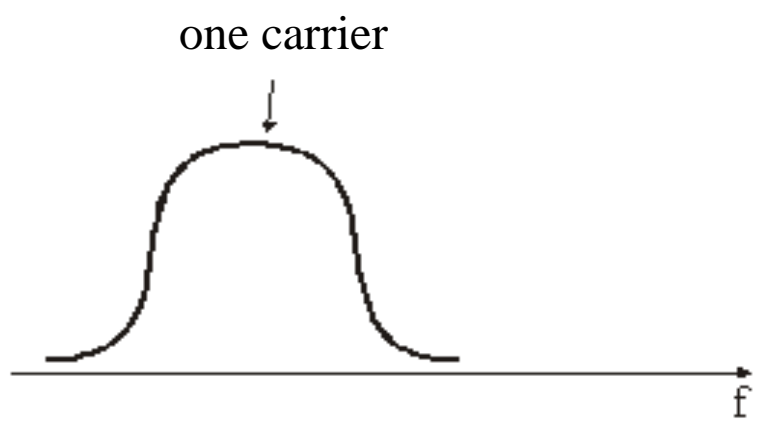

a) multiple subcarriers

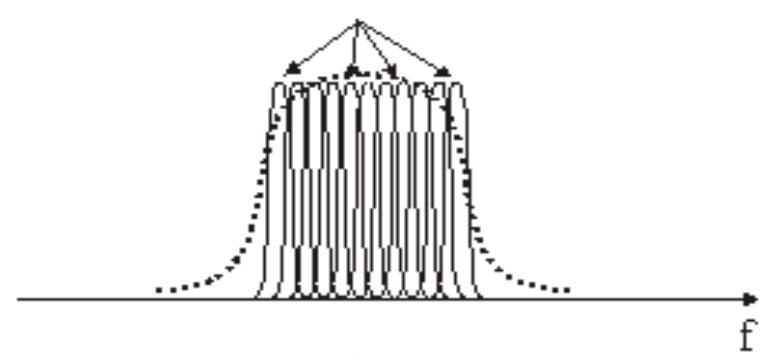

b)

Figure 1. Single carrier radio spectrum (a) and OFDM (b)

To fulfill the orthogonality conditions, the frequency range between the carriers must be constant and equal to $D f=1 / T U$, i.e., the whole number of frequency cycles of the difference $\mathrm{f} 2$ - $\mathrm{f} 1$ must correspond to the TU range. Example of COFDM signal in $8 \mathrm{~K}$ version of DVB-T standard.

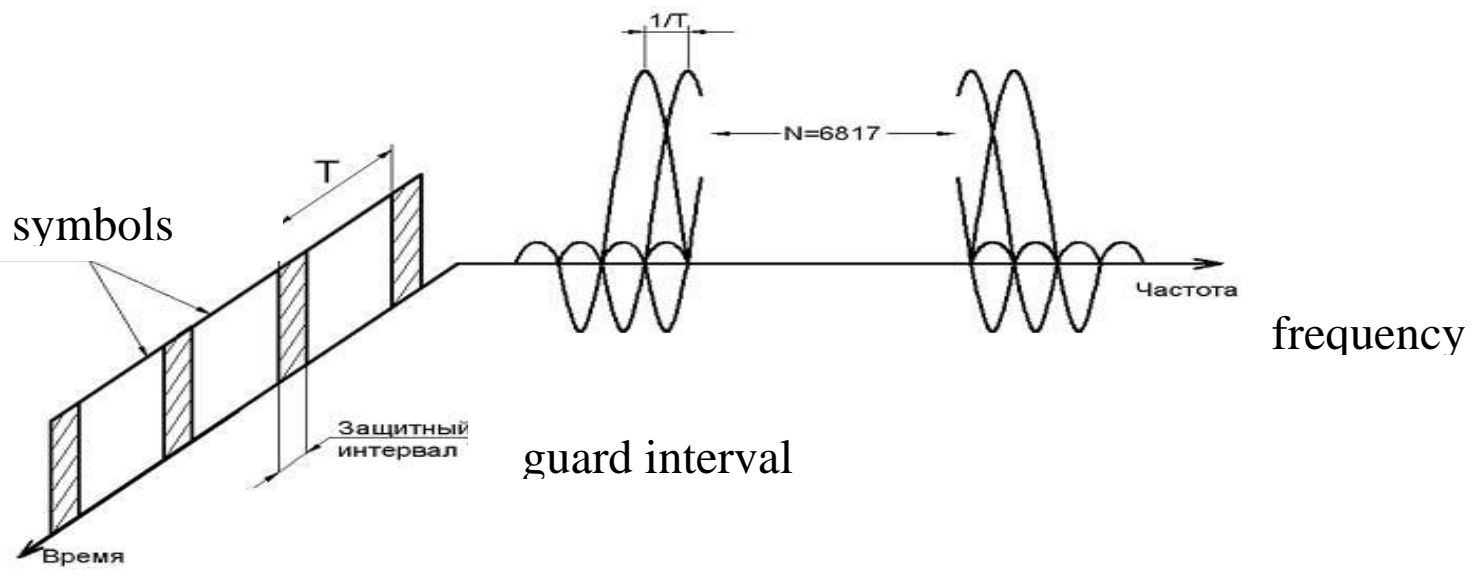

Figure 2. $\mathbf{C}$ time $\mathbf{8 K}$ DVB-T.

The threshold ratio of signal-to-noise for DVB-T is about 5-10 times better, taking into 
account the boundary effect.

This, in order to receive a DVB-T signal in dense urban conditions, the antenna must meet the following requirements:

- the size of the antenna should not exceed $1 / 2$ of the wavelength; - the antenna row may not exceed two layers;

- an antenna of the "waveguide" type must have more than one director;

- place the antenna in the maximum area of the standing wave.

Channel alignment is simplified because the OFDM signal can be viewed not as a fastmodulated broadband signal but as a plurality of slow-modulated narrowband signals.

The low level of characters allows the use of time intervals between characters, which overccman the mread of time and eliminates inter-character distortions (ISI).

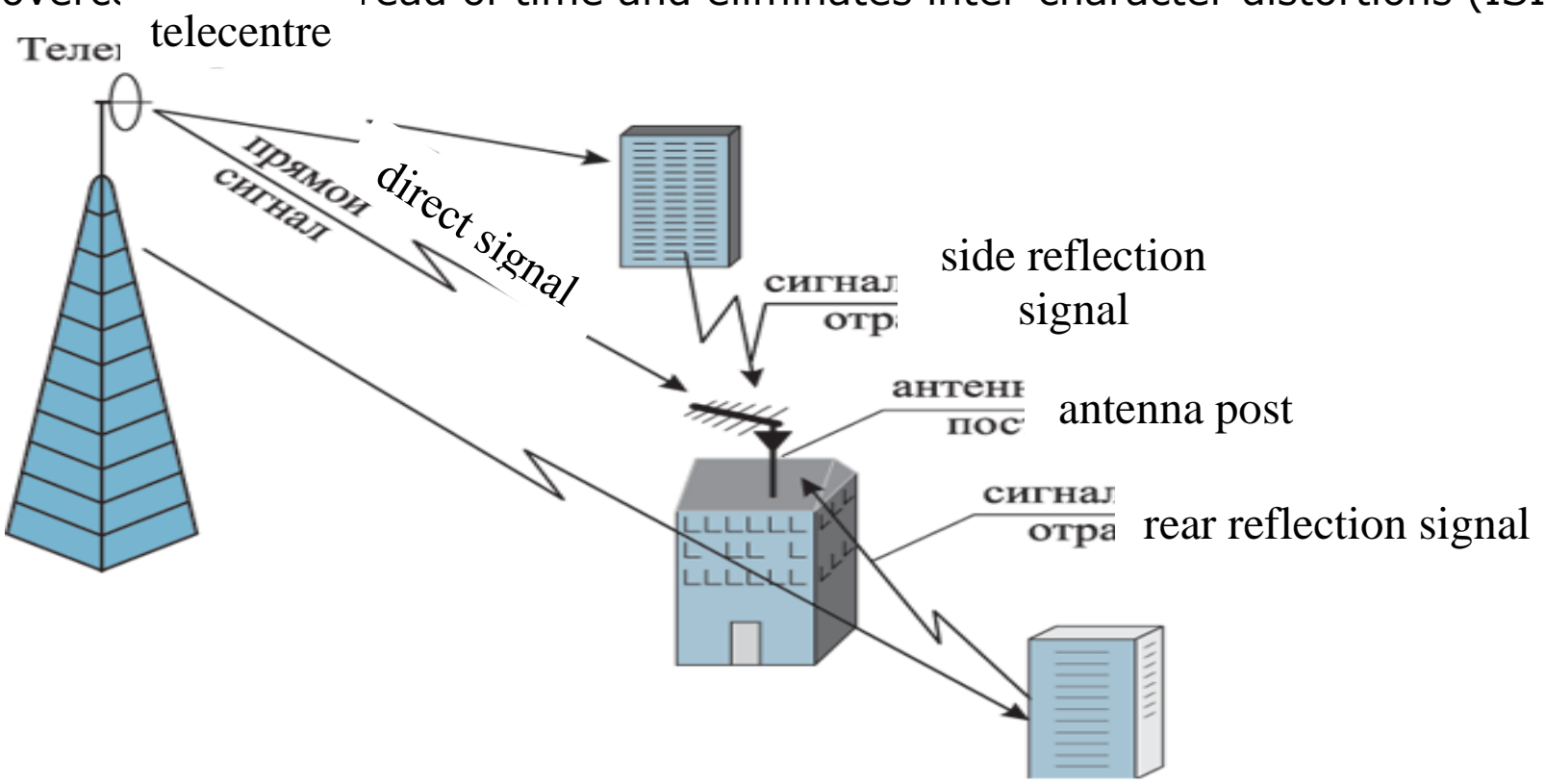

Figure 3. The principle of formation of a multipath signal

\section{Conclusion}

Mirror waves should be of two types: waves reflected from buildings and foreign objects, and waves reflected from the earth. Due to the small difference in the propagation time of the direct and reflected waves, the reflected waves on the ground cannot cause echo signals.

However, as a result of the noise, vertical waves are generated, which leads to a law of variable oscillation of the field strength as the height of the receiving antenna increases. 
This leads to the need to choose the correct antenna mounting height.

\section{References}

1. Television. Textbook, in Russian V.E. Under the auspices of Djakonia M. RiS. 1997; 1983.

2. S.Sh. Tadjibaev. Digital TV Tash. TEIS 1998

3. S.Sh. Tadjibaev. Image recovery structure. Tash. TEIS 1995

4. S.Sh. Tadjibaev. Image transmission camera. Tash. TEIS 1998

5. B.A. Lokshin Digital broadcasting: - from studio to TV viewer - M . : Company CYRUS SYSTEMS, $2001.446 \mathrm{p}$.

6. Artyushenko V.M., Shelukhin O.I., Afonin M.Yu. "Digital compression of video information and sound" I .: Moscow 2003. 430 s.

7. Kovalgin Yu.A., Vologdin E.I. "Digital coding of sound signals" I .: Crown print. St. Petersburg 2004, 230 p.

8. Theory of digital processing of video images. http://mirazhstd.narod.ru/index2.htm

\section{Internet resources:}

1. http://www.dvb.org

2. http://www.atsc.org

3. http://www.ieee.org

4. http://www.opentv.com 